\title{
Comparison of characteristics of selected metallic and metal oxide nanoparticles produced by picosecond laser ablation at 532 and $1064 \mathrm{~nm}$ wavelengths
}

\author{
Abubaker Hamad ${ }^{1} \cdot \operatorname{Lin} \mathrm{Li}^{1} \cdot \mathrm{Zhu} \mathrm{Liu}^{1,2}$
}

Received: 19 May 2016/Accepted: 7 September 2016/Published online: 20 September 2016

(C) The Author(s) 2016. This article is published with open access at Springerlink.com

\begin{abstract}
Picosecond laser generation of nanoparticles was only recently reported. The effect of laser wavelength in picosecond laser generation of nanoparticles is not yet fully understood. This investigation reports the new findings comparing the characteristics of $\mathrm{Au}, \mathrm{Ag}, \mathrm{Ag}-\mathrm{TiO}_{2}, \mathrm{TiO}_{2}$, $\mathrm{ZnO}$ and iron oxide nanoparticles generated by picosecond laser ablation in deionised water at 532 and $1064 \mathrm{~nm}$ laser wavelengths. The laser ablation was carried out at a fixed pulse width of $10 \mathrm{ps}$, a repetition rate of $400 \mathrm{kHz}$ and a scan speed of $250 \mathrm{~mm} / \mathrm{s}$. The nanoparticles were characterised by UV-Vis optical spectroscopy, transmission electron microscopy (TEM) and X-ray diffraction (XRD). The work shows that there is no noticeable difference in the size of the metal oxide nanoparticles produced at 532 and $1064 \mathrm{~nm}$, especially for the $\mathrm{TiO}_{2}$ and $\mathrm{ZnO}$ nanoparticles; however, a considerable size difference can be seen for metallic (e.g. $\mathrm{Au}$ ) and metallic compound (e.g. $\mathrm{Ag}-\mathrm{TiO}_{2}$ ) nanoparticles at the two wavelengths. It demonstrates that noble metals are more profoundly affected by laser wavelengths. The reasons behind these results are discussed. In addition, the work shows that there are different crystalline structures of the $\mathrm{TiO}_{2}$ nanoparticles at 1064 and $532 \mathrm{~nm}$ wavelengths.
\end{abstract}

Abubaker Hamad

abubaker.hamad75@yahoo.co.uk

1 Laser Processing Research Centre, School of Mechanical, Aerospace and Civil Engineering, The University of Manchester, Manchester M13 9PL, UK

2 School of Materials, The University of Manchester, Manchester M13 9PL, UK

\section{Introduction}

Laser ablation in deionised water has been used widely to produce metallic, bi-metallic and tri-metallic nanoparticles as well as metal oxides [1]. An advantage of laser production of nanoparticles is the high purity of the nanoparticles produced, special surface charge characteristics and easy preparation in comparison with chemical methods. It was found that various laser parameters such as laser power, energy density (fluence), beam spot size, scanning speed and media under which ablation takes place and wavelength [2,3], may be used to manipulate the size distribution and shape of the nanoparticles.

Nanosecond and picosecond lasers with different wavelengths have been used to produce different types of nanoparticles, although very few studies used picosecond lasers. For example, Baladi and Mamoory [4] used a nanosecond laser to produce $\mathrm{Al}$ nanoparticles at 1064 and $533 \mathrm{~nm}$ wavelengths in ethanol. It was shown that finer spherical particles and a higher rate of production of the nanoparticles can be produced at 1064 than at $533 \mathrm{~nm}$. In addition, it was shown that higher productivity and larger nanoparticles were produced at higher laser energy. Mortazavi et al. [5] produced smaller-sized palladium ( $\mathrm{Pd}$ ) nanoparticles at a greater production rate with a nanosecond laser in deionised water at $1064 \mathrm{~nm}$ (IR-Nd:YAG laser) than at $193 \mathrm{~nm}$ (UV ArF Excimer laser). It was also shown that the plasma temperature of the longer wavelength was considerably higher than that of the shorter wavelength because of the higher inverse Bremsstrahlung reaction rate to heat the induced plasma. In addition, the blue shift phenomena that occurred at the longer laser wavelength is evident that the plasma produced at $1064 \mathrm{~nm}$ is more energetic than that produced at $193 \mathrm{~nm}$. Furthermore, Kim et al. [6] studied the effects of using a 
nanosecond laser of different laser wavelengths and laser fluence on the production of palladium (Pd) nanoparticles in distilled water. It was found that the Pd nanoparticles produced at 532 and $355 \mathrm{~nm}$ wavelengths are more homogenous and smaller in size than those produced at $1064 \mathrm{~nm}$. It was concluded that increasing laser fluence leads to an increase in the size of the nanoparticles at all wavelengths. Chewchinda et al. [7] prepared the characteristics of spherical Si nanoparticles with nanosecond laser ablation in ethanol (10 ns and $10 \mathrm{~Hz})$ at 532 and $1064 \mathrm{~nm}$ laser wavelengths under the same energy density $\left(1.2 \mathrm{~J} / \mathrm{cm}^{2}\right)$. It was found that smaller nanoparticles and a narrower size distribution of Si nanoparticles were produced at $532 \mathrm{~nm}$ than those at $1064 \mathrm{~nm}$; the average sizes were about 3 and $7 \mathrm{~nm}$, respectively. In addition, a higher concentration of nanoparticles was obtained at shorter laser wavelengths. Imam et al. [2] found that smaller $\mathrm{Au}$ nanoparticles and a higher rate of productivity were generated by nanosecond laser ablation in water at $532 \mathrm{~nm}$ than those produced at $1064 \mathrm{~nm}$ wavelength. He et al. [8] produced $\mathrm{ZnO}$ nanoparticles by nanosecond laser ablation in a liquid medium at a wavelength of $355 \mathrm{~nm}$.

Intartaglia et al. [9] produced $\mathrm{Au}-\mathrm{Ag}$ nanoparticles by picosecond laser ablation in a liquid environment from an Ag target placed in a colloidal Au nanoparticles irradiated at different laser wavelengths. It was shown that the average size of the nanoparticles did not depend on the laser wavelength; their average sizes were 5,15 and $8.5 \mathrm{~nm}$ at 355, 532 and $1064 \mathrm{~nm}$ laser wavelengths, respectively. The picosecond laser operated at a laser pulse width of $60 \mathrm{ps}$ and a repetition rate of $20 \mathrm{~Hz}$ with maximum pulse energy of $115 \mathrm{~mJ}$ at $1064 \mathrm{~nm}, 55 \mathrm{~mJ}$ at $532 \mathrm{~nm}$ and $35 \mathrm{~mJ}$ at $355 \mathrm{~nm}$ wavelengths. Giorgetti et al. [10] prepared nanoparticles by picosecond laser ablation of metallic ( $\mathrm{Au}$ and $\mathrm{Ag}$ ) and semiconductor $(\mathrm{CdSe})$ target materials in water at fundamental (1064 nm-25 ps), second-harmonic $(532 \mathrm{~nm}-20 \mathrm{ps})$ and third-harmonic $(355 \mathrm{~nm}-15 \mathrm{ps})$ laser wavelengths. Different sizes of $\mathrm{Au}$ nanoparticles were produced: 5.2, 3.2 and $2.5 \mathrm{~nm}$ at 1064, 532 and $355 \mathrm{~nm}$ wavelengths, respectively. Hamad et al. [11] produced Ag$\mathrm{TiO}_{2}$ compound nanoparticles by picosecond laser ablation of an $\mathrm{Ag} / \mathrm{Ti}$ alloy target in deionised water at a wavelength of $1064 \mathrm{~nm}$ [11]. Silver nanoparticles have been produced by a picosecond laser in a liquid environment at wavelengths of $1064 \mathrm{~nm}$ [12], 1030 and $515 \mathrm{~nm}$ [13]. Giorgetti et al. [10] produced Ag nanoparticles at $1064 \mathrm{~nm}$ and postirradiated them at a wavelength of $532 \mathrm{~nm}$, and Nouneh et al. [14] used the 532-nm wavelength of a picosecond laser to post-irradiate the $\mathrm{Ag}$ nanoparticles on an indium tin oxide (ITO) substrate in an attempt to manipulate their size and change their optical absorption properties. Schwenke et al. [13] produced Ag nanoparticles in polyurethanedoped tetrahydrofuran at 1030 and $515 \mathrm{~nm}$ wavelengths of a picosecond laser (7 ps), and Menéndez-Manjón et al. [15] produced $\mathrm{Au}, \mathrm{Ag}$ and $\mathrm{AuAg}$ alloy nanoparticles using a picosecond-pulsed laser (7 ps) at a wavelength of $515 \mathrm{~nm}$ in liquid monomer. Liu et al. [16] produced $\mathrm{FeO}$ nanoparticles by a picosecond laser in poly(vinylpyrrolidone) (PVP) solution at a wavelength of $1064 \mathrm{~nm}$. They showed that the stability and particle size of the colloidal nanoparticles can be controlled via the PVP concentration because of the repulsive interaction and capping effects of PVP solution.

Despite the previous studies on laser wavelength effects in laser production of nanoparticles, the effect of laser wavelength in picosecond laser production of nanoparticles is not yet clear and the mechanisms involved are not clear. In this work, picosecond laser wavelengths of 532 and $1064 \mathrm{~nm}$ were used to produce $\mathrm{Au}, \mathrm{Ag}, \mathrm{Ag}-\mathrm{TiO}_{2}, \mathrm{TiO}_{2}$, $\mathrm{ZnO}$ and iron oxide nanoparticles in deionised water. The nanoparticles were then compared in terms of their sizes and morphology.

\section{Experimental materials and procedure}

\subsection{Materials}

$\mathrm{An} \mathrm{Au}$ target foil with dimensions of $65 \mathrm{~mm} \times$ $10 \mathrm{~mm} \times 0.2 \mathrm{~mm}$ with a purity of $99.99 \%$, an Ag target plate with dimensions of $25 \mathrm{~mm} \times 25 \mathrm{~mm} \times 2 \mathrm{~mm}$ and a purity of $99.99 \%$, a Ti/Ag alloy plate (3:1 at.\%) with the dimensions of $25 \mathrm{~mm} \times 25 \mathrm{~mm} \times 1 \mathrm{~mm}$ and $\mathrm{Ag}$ and $\mathrm{Ti}$ alloy components with purity levels of 99.95 and $99.7 \%$, respectively, a $\mathrm{Ti}$ target plate with the dimensions of $25 \mathrm{~mm} \times 25 \mathrm{~mm} \times 1 \mathrm{~mm}$ and a purity of $99.99+\%$, a Fe target foil with the dimensions of $30 \mathrm{~mm} \times 30 \mathrm{~mm} \times$ $0.3 \mathrm{~mm}$ with a purity of $99.95 \%$, and a Zn target plate with the dimensions of $25 \mathrm{~mm} \times 25 \mathrm{~mm} \times 2 \mathrm{~mm}$ with a purity of $99.99+\%$ were used to generate the $\mathrm{Au}, \mathrm{Ag}, \mathrm{Ag}-\mathrm{TiO}_{2}, \mathrm{TiO}_{2}$, $\mathrm{ZnO}$ and iron oxide nanoparticles in deionised water.

\subsection{Nanoparticle Production Procedure}

In this work, $\mathrm{Au}, \mathrm{Ag}, \mathrm{Ag}-\mathrm{TiO}_{2}, \mathrm{TiO}_{2}, \mathrm{ZnO}$ and iron oxide nanoparticles were produced via a dual-wavelength picosecond laser with wavelengths of 532 and $1064 \mathrm{~nm}$ (see Fig. 1a), respectively, in distilled water. The liquid solution was in the stationary condition. The target materials were placed individually on a stainless steel holder in a $100-\mathrm{ml}$ Pyrex glass vessel which contained $15-20 \mathrm{ml}$ of distilled water. The water level above the targets was fixed at around $2 \mathrm{~mm}$ in all experiments. The experimental set-up is shown in Fig. 1b. The ablation area was $5 \mathrm{~mm} \times 5 \mathrm{~mm}$ with a galvo scanning computer program, but on the surface of the samples it was approximately $3 \mathrm{~mm} \times 3 \mathrm{~mm}$ at the 

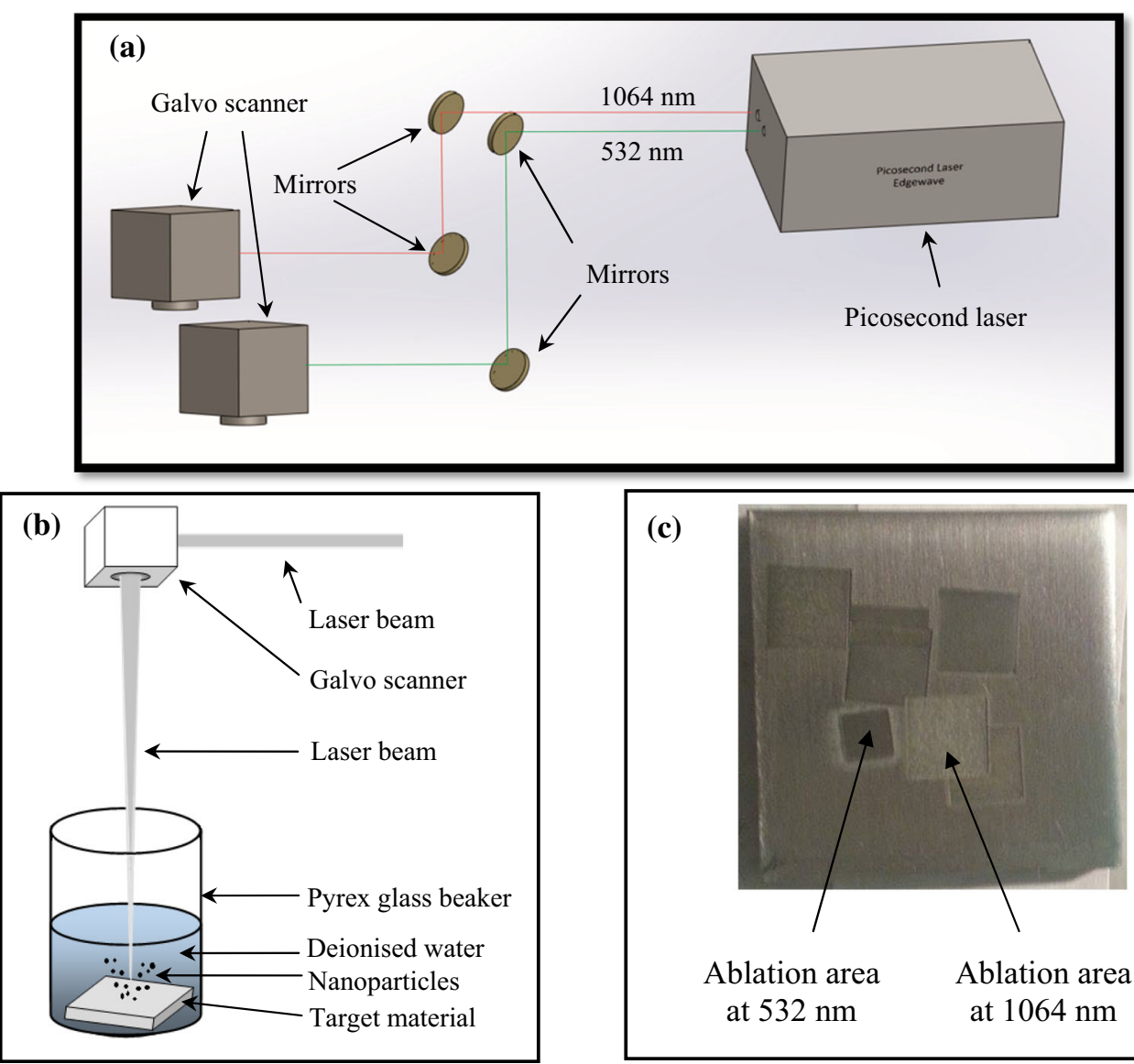

(c)

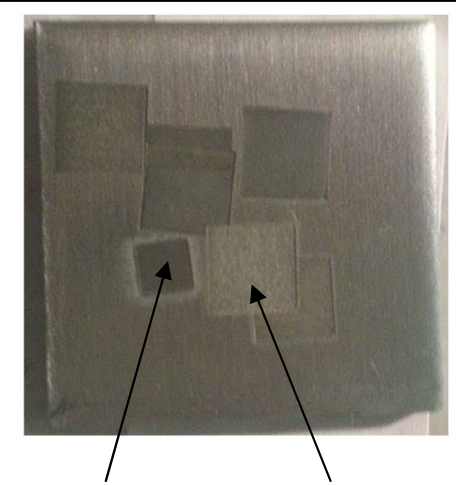
Ablation area
Ablation area at $532 \mathrm{~nm}$ at $1064 \mathrm{~nm}$

Fig. 1 Scheme of the picosecond laser with dual wavelength (a), experimental set-up for nanoparticle production (b) and ablation area on a sample at 532 and $1064 \mathrm{~nm}$ wavelengths (c)

wavelength of $532 \mathrm{~nm}$ and $4.65 \mathrm{~mm} \times 4.65 \mathrm{~mm}$ at $1064 \mathrm{~nm}$ (see Fig. 2c). Further details of the laser beam characteristics at both wavelengths are summarised in Table 1. Galvo scanners (SCANLAB hurry SCAN 20) were used to scan the laser beams over the target area in a raster pattern at both wavelengths.

\subsection{Material Characterisation and Sample Preparation Procedure}

The nanoparticles produced were characterised with a UVVis spectrometer (Analytic Jena, SPECORD 250, dual beam) in order to measure the absorption spectra of the colloidal nanoparticles. A transmission electron microscope (TEM) [Philips CM20 $200 \mathrm{kV}$ TEM (LaB6)] was used to examine the morphology and size distribution of the nanoparticles. X-ray diffraction (XRD) (BrukerD8Discover, step size $\left[{ }^{\circ} 2 \theta\right]=0.0200$ ) was used to investigate the crystalline structures of the nanoparticles. A copper micro-grid mesh (200 mesh) was used to prepare samples for the TEM analysis. The mesh was put on a glass slide on a hot plate. After depositing a drop of colloidal nanoparticles onto the mesh, the hot plate was turned on and the temperature was raised to about $45^{\circ} \mathrm{C}$. Before drying the drop completely, the mesh was wiped across the drop to collect more nanoparticles and disperse the nanoparticles uniformly, and then the drop was allowed to dry completely. This process was repeated twice to deposit a sufficient amount of nanoparticles on the copper microgrid mesh. The X-ray diffraction samples were prepared on glass slides; first, the colloidal nanoparticles were centrifuged for about $15 \mathrm{~min}$ using a microcentrifuge machine; then, they were dropped onto a glass slide and allowed to dry on a hot plate at about $40{ }^{\circ} \mathrm{C}$. This process was repeated several times to deposit a sufficient amount of nanoparticles on the slide.

\section{Results}

\subsection{Au Nanoparticles}

Figure 2a shows the optical absorption spectra of $\mathrm{Au}$ nanoparticles produced at 532 and $1064 \mathrm{~nm}$ in deionised water. The surface plasmon resonance of the nanoparticles was observed at 520 and $530 \mathrm{~nm}$ at the laser wavelengths 

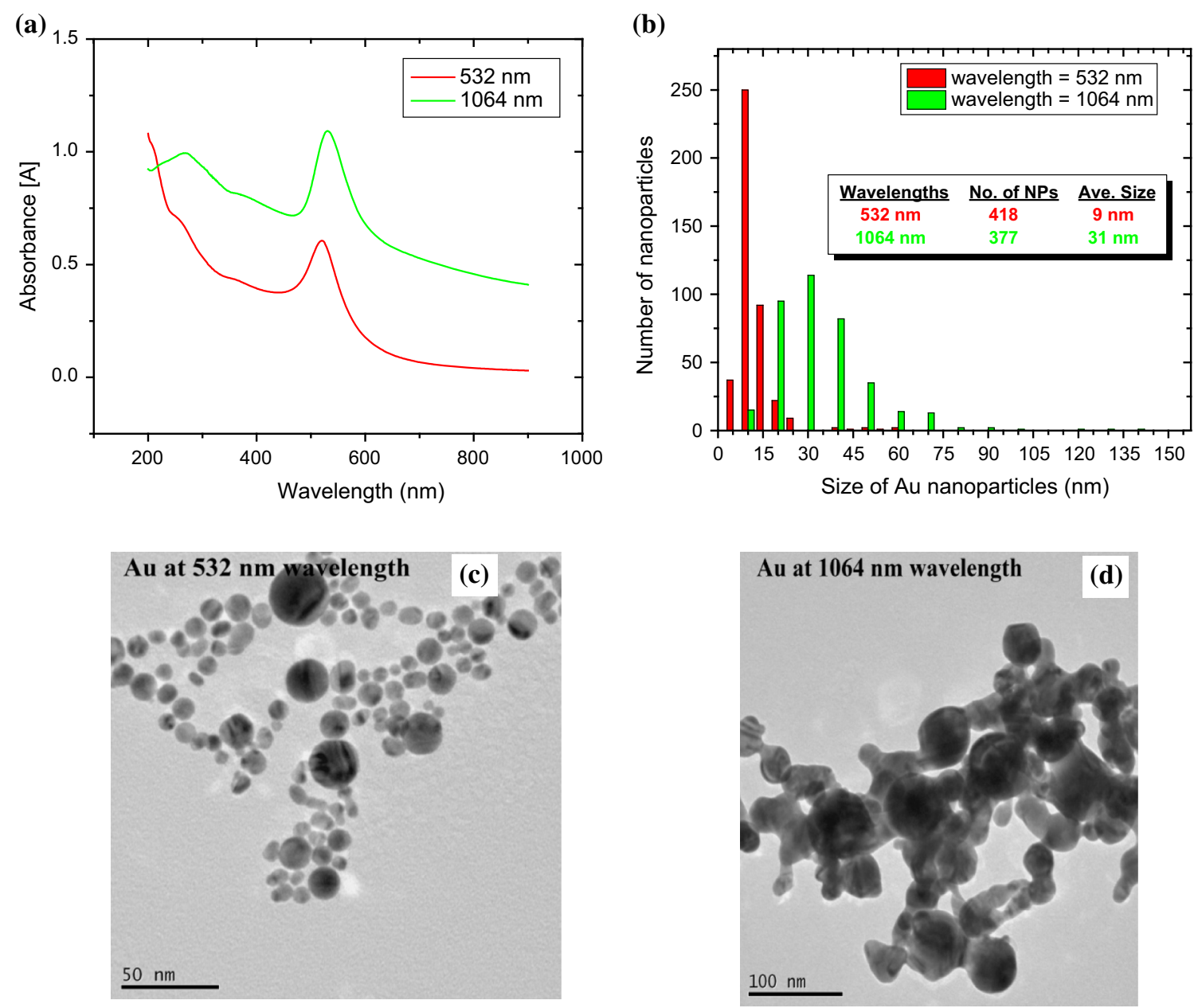

Fig. 2 Optical absorption spectra (a), histogram of the size distribution (b) and TEM images (c, d) of the Au nanoparticles produced by a picosecond laser at 532 and $1064 \mathrm{~nm}$ wavelengths in deionised water

Table 1 Characteristics and process parameters of the picosecond laser at both wavelengths (532 and $1064 \mathrm{~nm}$ )

\begin{tabular}{lll}
\hline Laser parameters & \multicolumn{2}{l}{ Wavelengths } \\
\cline { 2 - 3 } & $532 \mathrm{~nm}$ & $1064 \mathrm{~nm}$ \\
\hline Average power $(P)$ & $16.7 \mathrm{~W}$ & $27.5 \mathrm{~W}$ \\
Frequency $(f)$ & $400 \mathrm{kHz}$ & $400 \mathrm{kHz}$ \\
Laser pulse duration $(\tau)$ & $10 \mathrm{ps}$ & $10 \mathrm{ps}$ \\
Beam diameter at the laser output window & $3 \mathrm{~mm}$ & $3 \mathrm{~mm}$ \\
Focal length & $100 \mathrm{~mm}$ & $163 \mathrm{~mm}$ \\
Spot size $(D)$ & $32.5 \mu \mathrm{m}$ & $106 \mu \mathrm{m}$ \\
Scan speed $(v)$ & $250 \mathrm{~mm} / \mathrm{s}$ & $250 \mathrm{~mm} / \mathrm{s}$ \\
Laser pulse energy $\left(E_{\text {pulse }}\right)$ & $42 \mu \mathrm{J}$ & $69 \mu \mathrm{J}$ \\
Laser fluence $\left(F_{\text {laser }}\right)$ & $5 \mathrm{~J} / \mathrm{cm}^{2}$ & $0.8 \mathrm{~J} / \mathrm{cm}^{2}$ \\
\hline
\end{tabular}

of 532 and $1064 \mathrm{~nm}$, respectively. For the Au nanoparticles produced at the 532-nm laser wavelength, the intensity of optical absorption spectrum of the Au nanoparticles was reduced sharply, while at $1064 \mathrm{~nm}$ it increased and then decreased slowly. Figure $2 \mathrm{~b}$ shows the histogram of the size distribution. It can be noted that the Au nanoparticles produced at $532 \mathrm{~nm}$ are smaller in size than those produced at $1064 \mathrm{~nm}$, measuring 9 and $31 \mathrm{~nm}$, respectively, despite the fact that the laser fluence at $532 \mathrm{~nm}$ was much higher than that at $1064 \mathrm{~nm}$ showing more dominating effect of laser wavelength. Only about $4 \%$ of the Au NPs (generated at $532 \mathrm{~nm}$ ) are larger than $20 \mathrm{~nm}$. As shown in Fig. 2c, d, the Au nanoparticles generated at the shorter wavelength are more uniformly dispersed than those generated at the longer wavelength. The longer wavelength produced a chain of nanoparticles, with most of them agglomerated together. Meanwhile, the nanoparticles produced at the shorter wavelength can be seen individually.

\section{2 $\mathrm{Ag}-\mathrm{TiO}_{2}$ Compound Nanoparticles}

As shown in Fig. 3a, in general, the optical absorption spectra of $\mathrm{Ag}-\mathrm{TiO}_{2}$ compound nanoparticles produced by picosecond laser ablation in deionised water at 532 and 

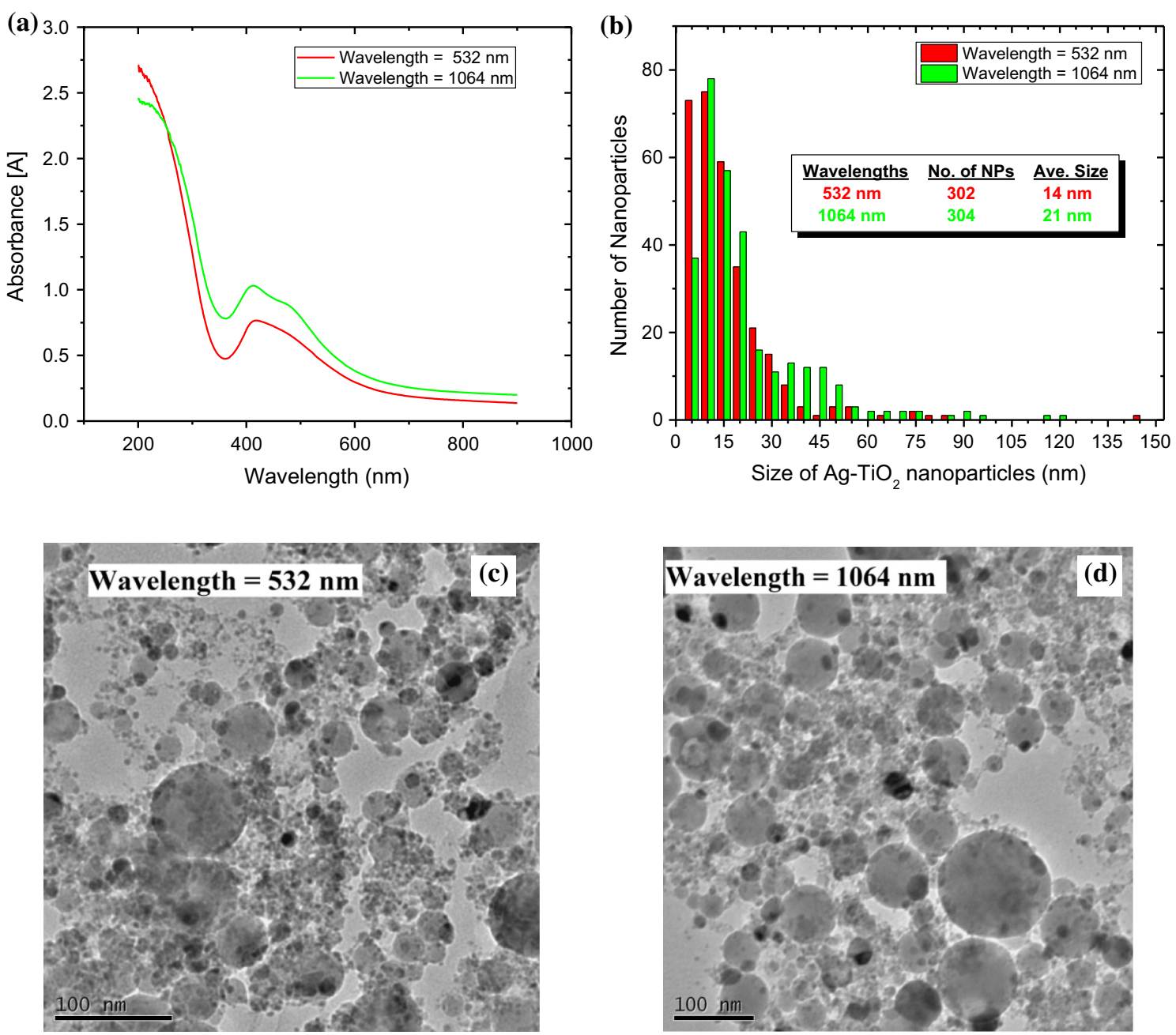

Fig. 3 Optical absorption spectra (a), histogram of the size distribution (b) and TEM images (c, d) of the $\mathrm{Ag}_{-} \mathrm{TiO}_{2}$ nanoparticles produced by a picosecond laser at 532 and $1064 \mathrm{~nm}$ wavelengths in deionised water

$1064 \mathrm{~nm}$ were similar, but the nanoparticles produced at the shorter wavelength had a slightly sharper plasmon peak (at $400 \mathrm{~nm}$ ) than that produced at the longer wavelength. The surface plasmon resonance of the nanoparticles at 532 and $1064 \mathrm{~nm}$ started at 410 and $415 \mathrm{~nm}$, respectively, extending to about $500 \mathrm{~nm}$ in the visible range.

The histogram of the size distribution in Fig. 3b shows that the 532-nm wavelength produced nanoparticles with a smaller average size $(14 \mathrm{~nm})$ in comparison with those produced at $1064 \mathrm{~nm}(21 \mathrm{~nm})$. As shown in the TEM images (Fig. 3c, d), spherical $\mathrm{Ag}-\mathrm{TiO}_{2}$ nanoparticles were produced at both wavelengths.

\section{3 $\mathrm{TiO}_{2}$ Nanoparticles}

Figure 4a shows the optical absorption spectra of $\mathrm{TiO}_{2}$ nanoparticles produced at 532 and $1064 \mathrm{~nm}$ in deionised water. The difference between the optical absorption spectra of the colloidal $\mathrm{TiO}_{2}$ nanoparticles generated at both wavelengths can be seen in the UV range. For nanoparticles produced at the 532-nm wavelength, the spectrum intensity dropped sharply at the UV wavelength earlier than those produced at $1064 \mathrm{~nm}$ wavelength. Both spectra have the same characteristics in the visible range. In spite of their different optical absorption spectra, the histogram of the size distribution (Fig. 4b) shows that there is a similarity between the size distributions of the $\mathrm{TiO}_{2}$ nanoparticles generated at both laser wavelengths, in that the average size and size distribution are close to each other. The average sizes of the nanoparticles produced at the 532 and $1064 \mathrm{~nm}$ were 34 and $32 \mathrm{~nm}$, respectively. The TEM images (Fig. 4c, d) show that spherical $\mathrm{TiO}_{2}$ nanoparticles were produced at both wavelengths.

Figure 5 shows the XRD pattern of the $\mathrm{TiO}_{2}$ nanoparticles produced at different wavelengths. The nanoparticles produced at $532 \mathrm{~nm}$ wavelength are crystalline with mixed anatase, rutile and brookite phases, but the nanoparticles produced at $1064 \mathrm{~nm}$ wavelength are crystalline with 

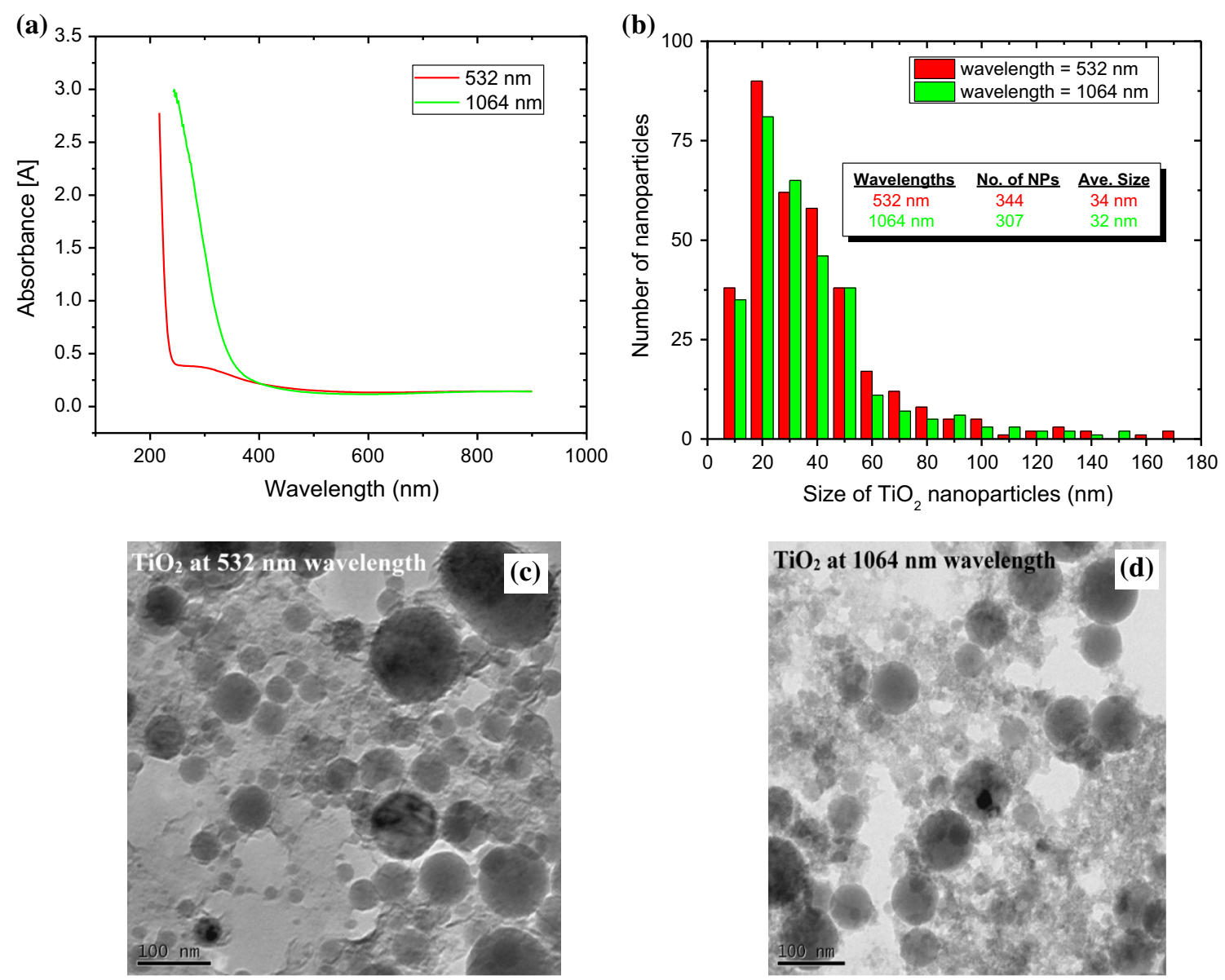

Fig. 4 Optical absorption spectra (a), histogram of the size distribution (b) and TEM images (c, d) of the $\mathrm{TiO}_{2}$ nanoparticles produced by a picosecond laser at 532 and $1064 \mathrm{~nm}$ wavelengths in deionised water

mixed rutile and brookite. In general, the same peaks were not observed in both samples; thus, the samples have not the same crystalline phases. In other words, the change in laser wavelengths has a noticeable effect on the phase of the $\mathrm{TiO}_{2}$ nanoparticles.

The peak positions $2 \theta=37.5^{\circ}$ and $63.3^{\circ}$ are attributed to the anatase $\mathrm{TiO}_{2}$ phases (004) and (204), respectively $[17,18]$. The peak positions $2 \theta=36^{\circ}, 41^{\circ}, 54^{\circ}$ and $63.85^{\circ}$ are attributed to the rutile $\mathrm{TiO}_{2}$ phases (101), (111), (211) and (310), respectively $[17,19]$. In addition, the peaks at $2 \theta=32.5^{\circ}$ are indicative of the brookite phase of the $\mathrm{TiO}_{2}$ nanoparticles $[20,21]$. A strong rutile peak was observed for the 532-nm laser wavelength at $27.5^{\circ}$ [22]. In addition, small peaks at $48^{\circ}$ and $68.3^{\circ}$ were observed at $532 \mathrm{~nm}$ which indicate the anatase phase [23, 24], and the peaks at $56.25^{\circ}$ and $70^{\circ}$ represent the rutile phase $[23,25]$ of the $\mathrm{TiO}_{2}$ nanoparticles.

\subsection{Iron Oxide Nanoparticles}

Figure 6a shows the optical absorption spectra of iron oxide nanoparticles produced at 532 and $1064 \mathrm{~nm}$ in deionised water. Both sets of nanoparticles have almost exactly the same characteristics. The histogram of the size distribution (see Fig. 6b) shows that smaller iron oxide nanoparticles were produced at $1064 \mathrm{~nm}$, measuring about $21 \mathrm{~nm}$ in average size in comparison with those produced at $532 \mathrm{~nm}$ (about $28 \mathrm{~nm}$ in average size). It can be observed that more than $50 \%$ of the measured nanoparticles measured under $20 \mathrm{~nm}$. The TEM images (Fig. 6c, d) show that spherical iron oxide nanoparticles were produced at both wavelengths. The nanoparticles are magnetic.

Figure 7 shows the X-ray diffraction of the iron oxide nanoparticles produced by picosecond laser in deionised water with different wavelengths (532 and $1064 \mathrm{~nm}$ ). The nanoparticles are crystalline with mixed $\mathrm{Fe}, \mathrm{FeO}$ and $\mathrm{Fe}_{3} \mathrm{O}_{4}$. The peak positions of $2 \theta=18.28^{\circ}, 30^{\circ}, 35.42^{\circ}$, $43^{\circ}, 53.4^{\circ}, 56.92^{\circ}, 62.5^{\circ}$ and $73.95^{\circ}$ are attributed to the anatase $\mathrm{Fe}_{3} \mathrm{O}_{4}$ phases (111), (220), (311), (400), (422), (511), (440) and (533), respectively [26, 27]. The peak positions $2 \theta=61^{\circ}$ (at the 532-nm wavelength) and 73.1 ${ }^{\circ}$ are attributed to the $\mathrm{FeO}$ phases (220), and (311), respectively $[28,29]$. In addition, the peaks at $2 \theta=44.67^{\circ}, 65^{\circ}$ and $82.33^{\circ}$ are indicative of the Fe phases (110), (200) and 
Fig. 5 XRD images of $\mathrm{TiO}_{2}$ nanoparticles produced by picosecond laser in deionised water with different wavelengths (532 and $1064 \mathrm{~nm}$ )

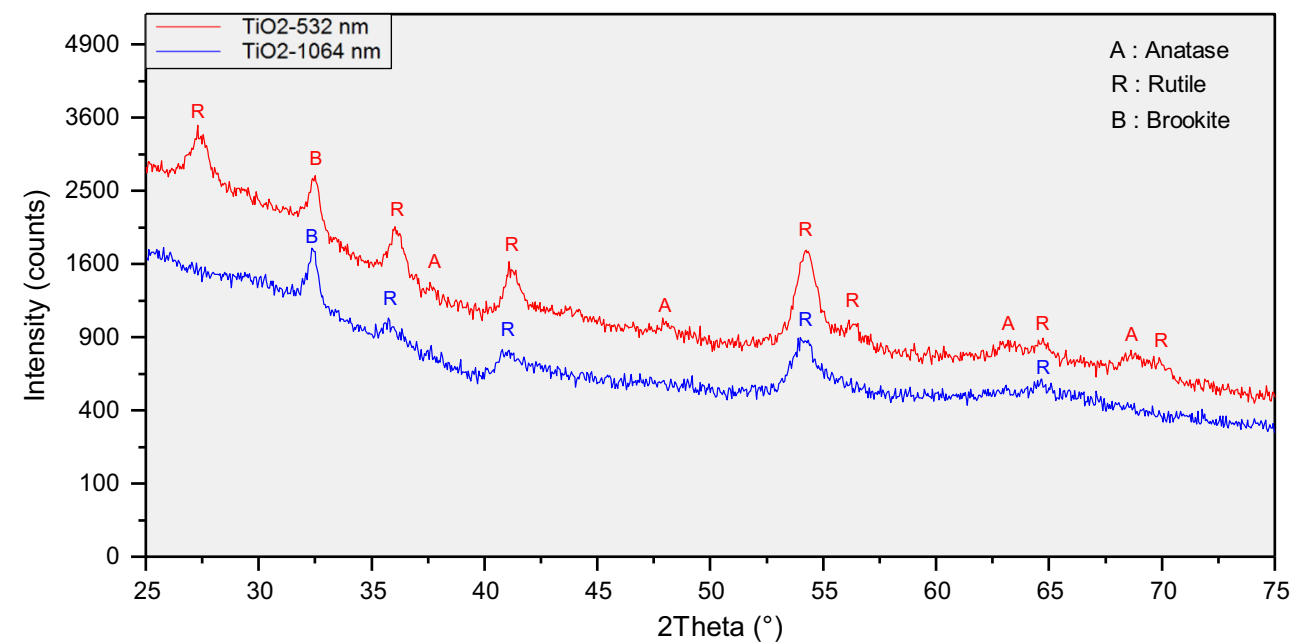

(a)

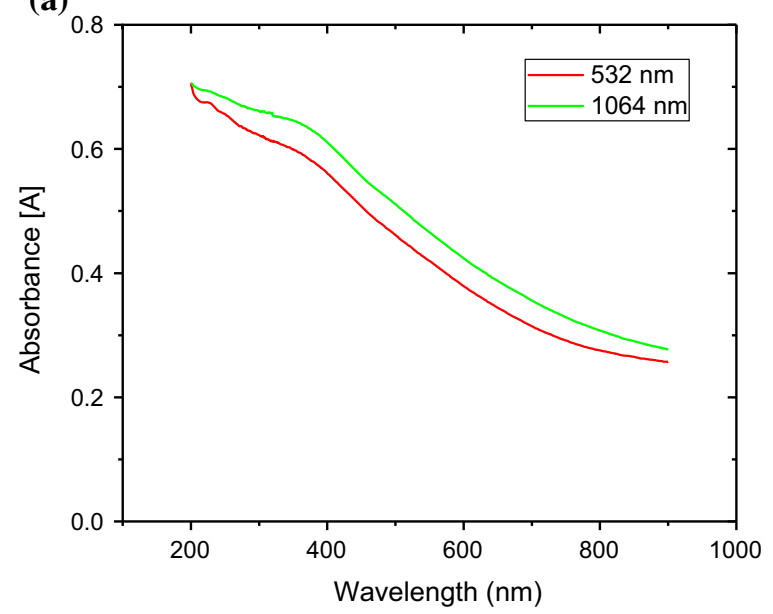

(b)
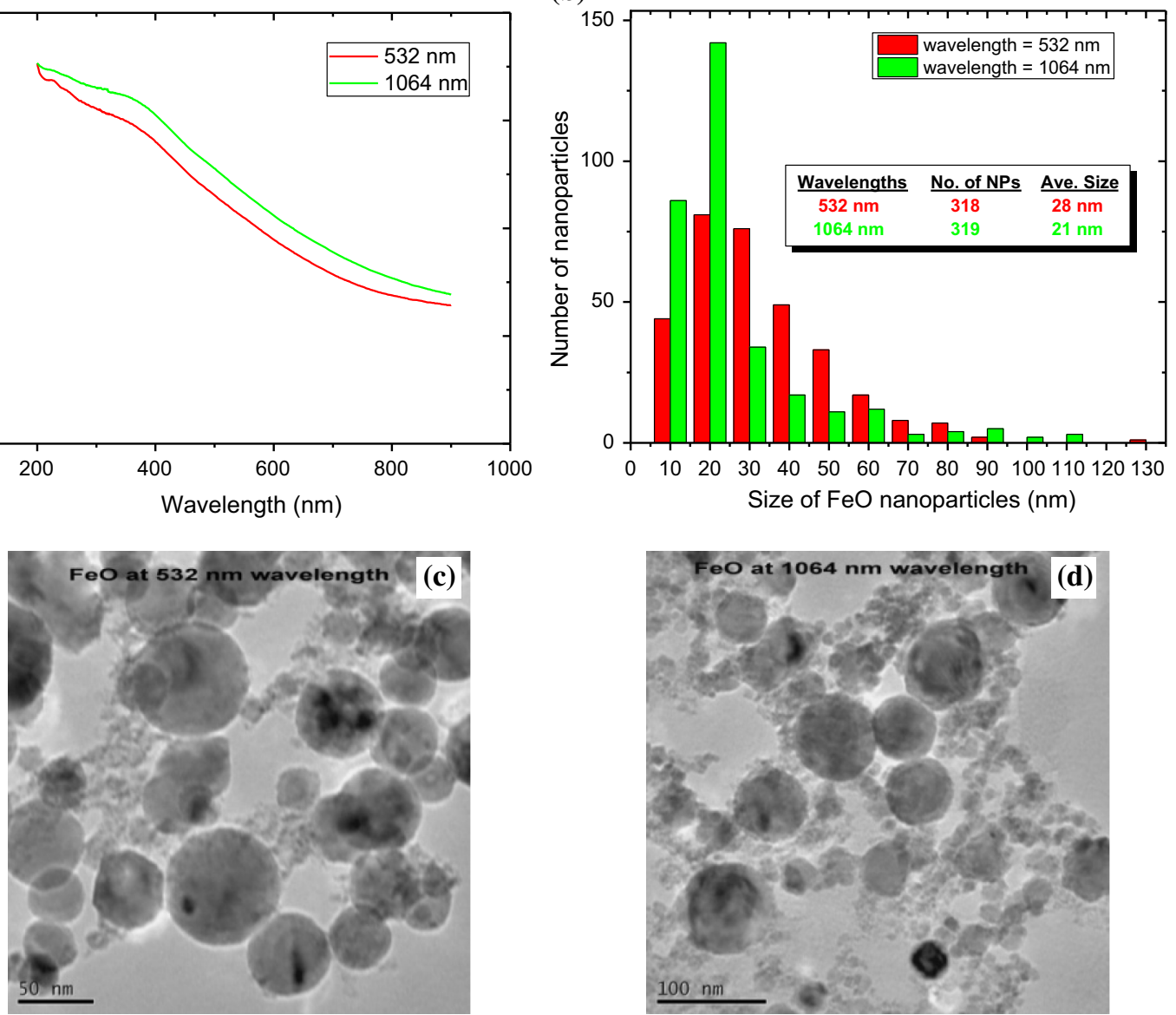

Fig. 6 Optical absorption spectra (a), histogram of the size distribution (b) and TEM images (c, d) of the iron oxide nanoparticles produced by a picosecond laser at 532 and $1064 \mathrm{~nm}$ wavelengths in deionised water

(211), respectively [30]. The diffraction peaks at planes (111), (220), (311), (400), (422), (511) and (440) are the characteristic peaks of $\mathrm{Fe}_{3} \mathrm{O}_{4}$ crystals with a cubic spinel structure and corresponded to a cubic unit cell [26, 31], or the inverse-spinel structure $\left(\mathrm{Fe}_{3} \mathrm{O}_{4}\right)$ [32].

\subsection{ZnO Nanoparticles}

$\mathrm{ZnO}$ nanoparticles were produced by the picosecond laser at the two wavelengths noted above. It can be seen from Fig. 8a that their optical absorption spectra are similar, 


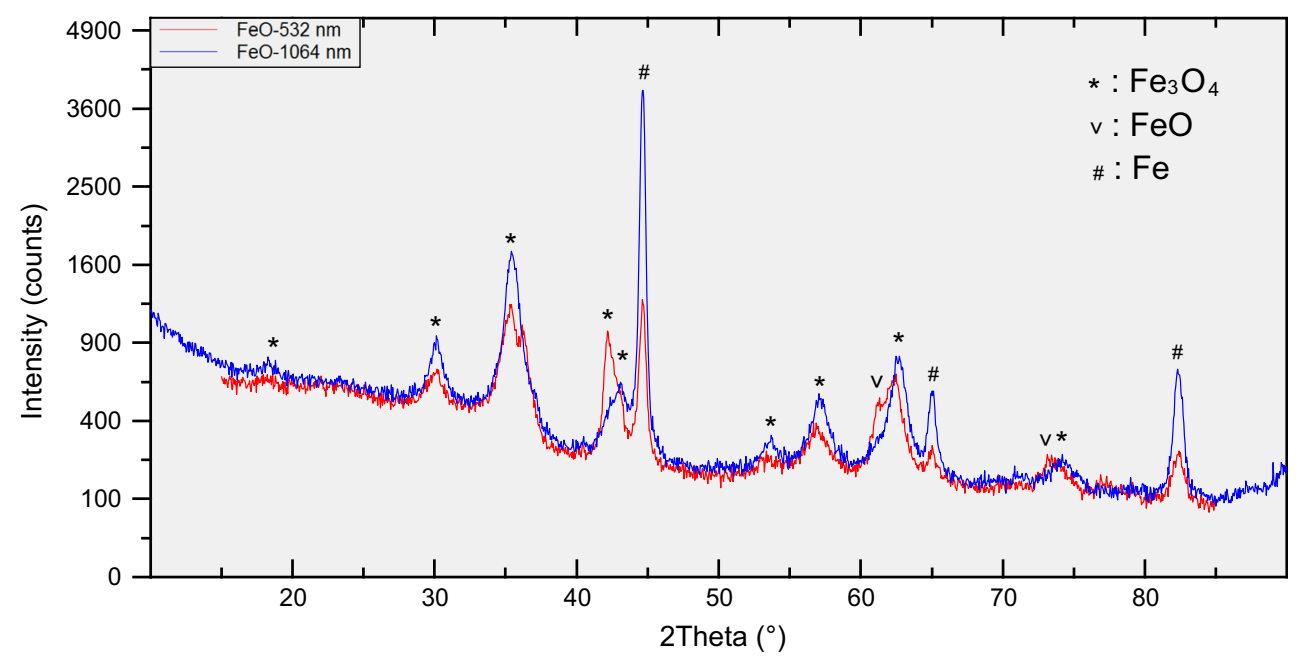

Fig. 7 XRD images of iron oxide nanoparticles produced by picosecond laser in deionised water with different wavelengths (532 and 1064 nm)
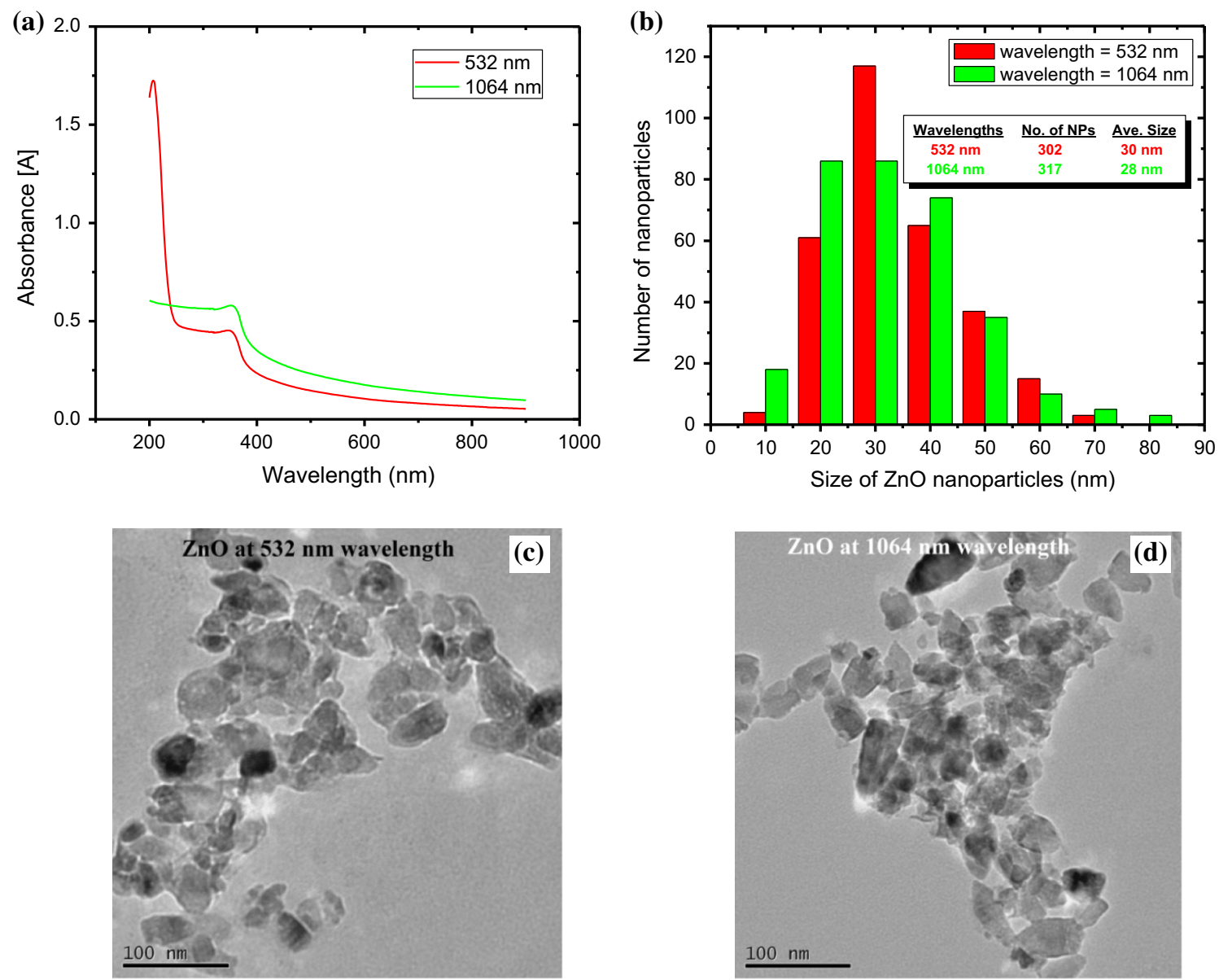

Fig. 8 Optical absorption spectra (a), histogram of the size distribution (b) and TEM images (c, d) of the ZnO nanoparticles produced by a picosecond laser at 532 and $1064 \mathrm{~nm}$ wavelengths in deionised water

except in the range of $200-250 \mathrm{~nm}$. The nanoparticles produced at $532 \mathrm{~nm}$ initially exhibited higher absorbance, which then decreased sharply. On the other hand, the intensity of absorption spectrum produced at $1064 \mathrm{~nm}$ was initially lower. The histogram of the size distribution in Fig. 8b shows that there is no significant effect of the 


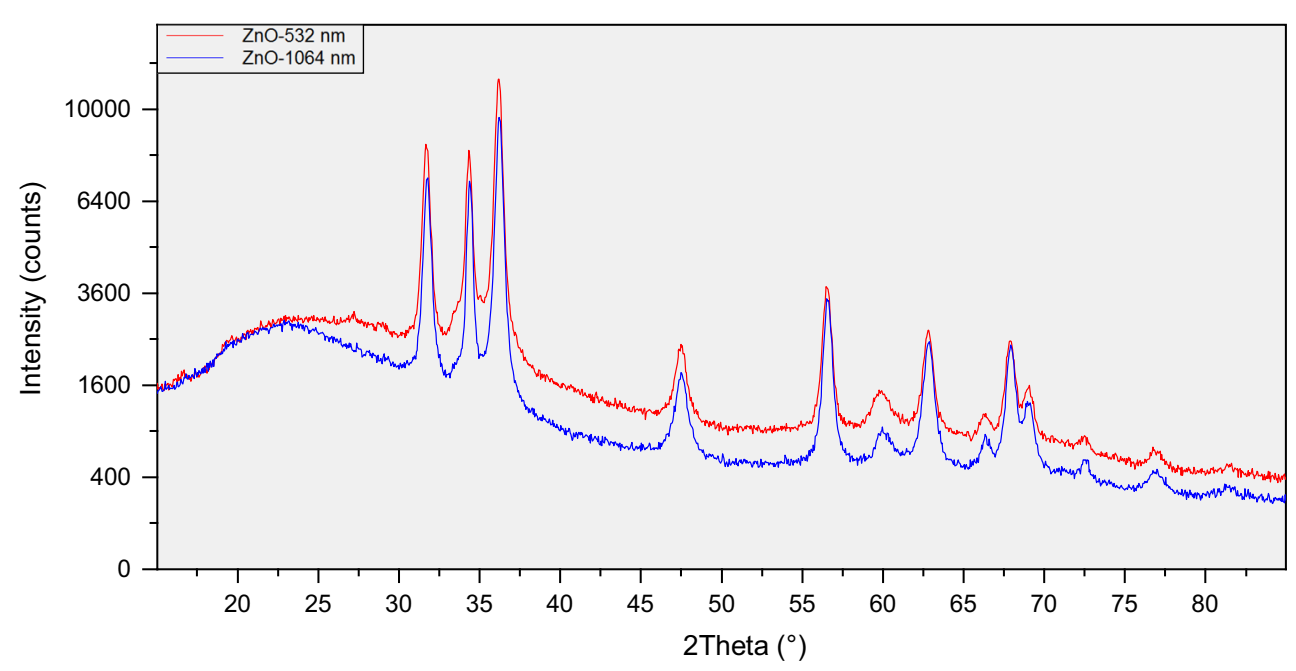

Fig. 9 XRD images of $\mathrm{ZnO}$ nanoparticles produced by picosecond laser in deionised water with different wavelengths (532 and $1064 \mathrm{~nm})$

wavelengths on the size of the nanoparticles. The TEM images (Fig. 8c, d) show that the $\mathrm{ZnO}$ nanoparticles have irregular shapes, but the majority are pin-shaped.

Figure 9 shows the XRD of the $\mathrm{ZnO}$ nanoparticles produced by picosecond laser in deionised water with different wavelengths (532 and $1064 \mathrm{~nm}$ ). A number of Bragg reflections with $2 \theta$ values of $31.76^{\circ}, 34.4^{\circ}, 36.25^{\circ}$, $47.55^{\circ}, 56.59^{\circ}, 62.85^{\circ}, 66.37^{\circ}, 67.94^{\circ}, 69^{\circ}, 72.56^{\circ}, 76.95^{\circ}$ and $81.37^{\circ}$ are observed corresponding to (100), (002), (101), (102), (110), (103), (200), (112), (201), (004), (202) and (104) planes, respectively, they showing a typical XRD pattern of $\mathrm{ZnO}$ nanoparticles (ICPDS card No. 89.1397) [33]. Almost all the peaks fully match the $\mathrm{ZnO}$ hexagonal phase of JCPDF No. 36-1451 [34]. Very similar values have also been reported by Arefi and Saeed [35], Dutta and Bichitra [36] and Prabhu et al. [34]. A peak at $60^{\circ}$ was observed at both wavelengths; this might be due to the glass substrate. Here, both spectra had exactly the same characteristics, which indicates that the changing wavelengths have no effect on the crystalline structures of the $\mathrm{ZnO}$ nanoparticles.

\subsection{Ag nanoparticles}

An unexpected finding of this work is the inability to produce silver nanoparticles from a pure silver plate material at the 532-nm wavelength. As shown in Fig. 10a, when attempting the above experiment, the optical absorption spectra of the $\mathrm{Ag}$ nanoparticles did not show any peak. This indicates that no silver nanoparticles were present in the solution. Even when the ablation process was continued for about $30 \mathrm{~min}$ and carried out at different repetition rates, $\mathrm{Ag}$ nanoparticles were not produced and the colour of the solution (deionised water) did not change. In contrast, the optical absorption spectra of the $\mathrm{Ag}$ nanoparticles produced at $1064 \mathrm{~nm}$ wavelength showed a strong surface plasmon resonance peak at a wavelength of $405 \mathrm{~nm}$ and the colour of the colloidal nanoparticles was yellow. The average size of the Ag nanoparticles produced at the 1064-nm wavelength was $29 \mathrm{~nm}$ (see Fig. 10b). As shown in Fig. 10c, the TEM images of the Ag nanoparticles produced at $1064 \mathrm{~nm}$ are semispherical in shape, but some have pentagonal and hexagonal shapes.

\section{Discussion}

\subsection{Effects of Wavelengths on the Size of the Nanoparticles}

$\mathrm{Au}, \mathrm{Ag}, \mathrm{Ag}-\mathrm{TiO}_{2}, \mathrm{TiO}_{2}, \mathrm{ZnO}$ and iron oxide nanoparticles were produced at both laser wavelengths 532 and $1064 \mathrm{~nm}$, with the exception of $\mathrm{Ag}$ nanoparticles that could not be produced at the wavelength of $532 \mathrm{~nm}$. The TEM images and the size distribution histogram show that significantly smaller $\mathrm{Au}$ and $\mathrm{Ag}-\mathrm{TiO}_{2}$ nanoparticles were produced at $532 \mathrm{~nm}$, although slightly smaller $\mathrm{TiO}_{2}, \mathrm{ZnO}$ and iron oxide nanoparticles were produced at $1064 \mathrm{~nm}$. As shown in Table 2, there is no noticeable difference in the size of the metal oxide nanoparticles produced at 532 and $1064 \mathrm{~nm}$, especially for the $\mathrm{TiO}_{2}$ and $\mathrm{ZnO}$ nanoparticles; however, a considerable size difference can be seen for the $\mathrm{Au}$ and $\mathrm{Ag}-\mathrm{TiO}_{2}$ nanoparticles. It can therefore be ascertained that noble metals are more profoundly affected by laser wavelengths, as almost all of the small $\mathrm{Ag}-\mathrm{TiO}_{2}$ nanoparticles are Ag [37].

According to the photon energy equation $E=h c / \lambda$, the shorter the photon's wavelengths, the higher its energy. At a wavelength of $532 \mathrm{~nm}$, green laser pulses have higher photon energy $(2.33 \mathrm{eV})$ that reaches the target material in 

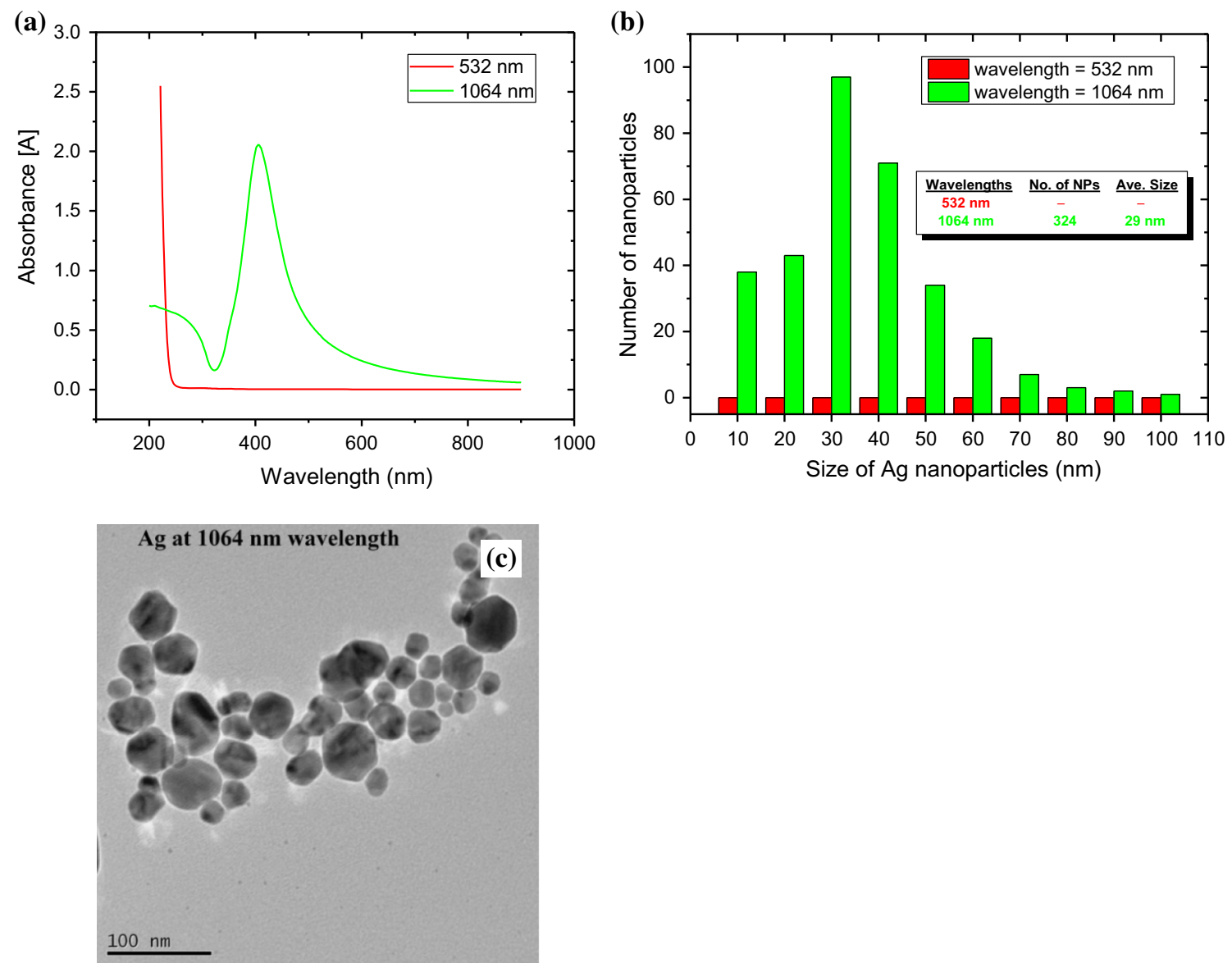

Fig. 10 Optical absorption spectra (a), histogram of the size distribution (b) and TEM images (c) of the Ag nanoparticles produced by a picosecond laser at $1064 \mathrm{~nm}$ wavelength in deionised water

Table 2 Average size of $\mathrm{Au}$, $\mathrm{Ag}-\mathrm{TiO}_{2}, \mathrm{Ag}, \mathrm{TiO}_{2}$, iron oxide and $\mathrm{ZnO}$ nanoparticles produced by picosecond laser at $532 \mathrm{~nm}$ and $1064 \mathrm{~nm}$

\begin{tabular}{llllll}
\hline Nanoparticles & \multicolumn{2}{l}{ Average size at: } & & As wavelength increased, the NP size is decreased or increased by \\
\cline { 2 - 3 } \cline { 5 - 6 } & $532 \mathrm{~nm}$ & $1064 \mathrm{~nm}$ & & Decreased & Increased \\
\hline $\mathrm{Au}$ & $9 \mathrm{~nm}$ & $31 \mathrm{~nm}$ & - & $22 \mathrm{~nm}$ \\
$\mathrm{Ag}-\mathrm{TiO}_{2}$ & $14 \mathrm{~nm}$ & $21 \mathrm{~nm}$ & - & $7 \mathrm{~nm}$ \\
$\mathrm{Ag}$ & - & $29 \mathrm{~nm}$ & - & - \\
$\mathrm{TiO}_{2}$ & $34 \mathrm{~nm}$ & $32 \mathrm{~nm}$ & $2 \mathrm{~nm}$ & - \\
$\mathrm{Iron}$ oxide & $28 \mathrm{~nm}$ & $21 \mathrm{~nm}$ & $7 \mathrm{~nm}$ & - \\
$\mathrm{ZnO}$ & $30 \mathrm{~nm}$ & $28 \mathrm{~nm}$ & $2 \mathrm{~nm}$ &
\end{tabular}

comparison with the 1064-nm wavelength, while the IR laser pulses of which have lower photon energy $(1.16 \mathrm{eV})$ reaching the target material. In general, the 532-nm wavelength is more effective at producing smaller $\mathrm{Au}$ and Ag nanoparticles than the 1064-nm wavelength. This is because the fragmentation by $1064 \mathrm{~nm}$ photons only affects the larger nanoparticles, which have a high extinction coefficient in the near-infrared region. In contrast, the fragmentation produced at $532 \mathrm{~nm}$ leads to a reduction in the size of the nanoparticles in the colloidal solution because this wavelength $(532 \mathrm{~nm})$ is in the range of the surface plasmon peak position of the $\mathrm{Au}$ and $\mathrm{Ag}$ nanoparticles [3]. Au nanoparticles are particularly affected by the 532-nm wavelength, because its surface plasmon resonance is in the range of 532-530 $\mathrm{nm}$, very close to the 532-nm wavelength. It is worth mentioning that the $\mathrm{Ag}$ nanoparticles were produced with a $\mathrm{Ti} / \mathrm{Ag}$ alloy material target, but no Ag nanoparticles were produced with pure Ag target material in deionised water at $532 \mathrm{~nm}$ wavelength. Even when the laser parameters such as power and frequency were changed, the $\mathrm{Ag}$ nanoparticles were not generated when using pure Ag target plate. The reason 
behind this is the changing physical properties of the Ag in $\mathrm{Ti} / \mathrm{Ag}$ alloy material, because the grindability of some Ti/ Ag alloy materials is superior to pure titanium, which leads to a "decrease in the elongation caused by the precipitation of small amounts of fine intermetallic compounds" [38]. The grindability may act as a driving force on the $\mathrm{Ag}$ material, causing it to be released from the target material, or the ablation of both $\mathrm{Ag}$ and $\mathrm{Ti}$ as an intermetallic compound such as $\mathrm{AgTi}_{3}$, as it is a composition of the Ti/ $\mathrm{Ag}$ alloy sample target [11]. Here the $\mathrm{Ag}-\mathrm{TiO}_{2}$ nanoparticles are also smaller because they have strong wide peak spectra, extending from 400 to $500 \mathrm{~nm}$ (see Fig. 3a).

Ag nanoparticles were not produced at the 532-nm wavelength with the picosecond laser (10 ps). This may be a result of the strong absorption of silver due to their surface plasmon resonance, as Schwenke et al. [13] showed that the productivity of silver nanoparticles at a $515-\mathrm{nm}$ wavelength of a picosecond laser decreases over the ablation process time, while at $1030 \mathrm{~nm}$ the productivity is constant. Another reason behind the failure to produce $\mathrm{Ag}$ nanoparticles at the 532-nm wavelength might be due to the saturable and reverse saturable absorption in silver nanoparticles at $532 \mathrm{~nm}$ using picosecond laser pulses; this phenomenon was observed by Gurudas et al. [39] in Ag nanodots prepared using the pulsed laser deposition method.

$\mathrm{Au}$ nanoparticles are more affected by the wavelengths than the other types. A red shift can be seen in the optical absorption spectra of the Au nanoparticles as the nanoparticle production laser wavelength is increased from 532 to $1064 \mathrm{~nm}$. This means that smaller Au nanoparticles are produced at the shorter wavelength. In addition, the shorter wavelength produced a narrower size distribution with separate nanoparticles in comparison with those produced at the longer wavelength which formed particle chains. In addition to the proximity of the 532-nm wavelength to the surface plasmon resonance peak of $\mathrm{Au}$ nanoparticles, another reason behind the smaller size of these nanoparticles at this wavelength might be that the shorter wavelength disperses over a smaller, thinner area on the target, which leads to the ablation of a smaller amount of materials; as a result, smaller nanoparticles are generated in the solution. In contrast, the longer wavelength disperses more widely in the target material, leading to the ablation of more materials, which in turn generates larger nanoparticles. Furthermore, the inter-particle separation can be seen clearly among the $\mathrm{Au}$ nanoparticles produced at $532 \mathrm{~nm}$, whereas almost all of the $\mathrm{Au}$ nanoparticles produced at $1064 \mathrm{~nm}$ are stuck together, forming chains. Rong et al. [40, 41] showed that if the inter-particle separations $(\Delta)$ are larger than the particle diameter $(D)(\Delta>D)$, "the near-field interaction between the particles is small and the resonance wavelength $\lambda_{\text {res }}$ is that of an individual particle", but if the inter-particle separations are smaller than the particle diameter $(\Delta>D)$, "the plasmons in the individual particles couple and the resonance wavelength $\lambda_{\text {res }}$ red shifts with decreasing separation". They observed the red-shift phenomena while increasing the intensity ratio $\left(R=I_{580 \mathrm{~nm}} / I_{530 \mathrm{~nm}}\right)$. Here red-shift phenomena of the $\mathrm{Au}$ nanoparticles' optical absorption spectra can be seen with the longer laser wavelength because the nanoparticles produced at the longer wavelength are joined together and there is no distance between them. Giorgetti et al. [10] attributed the different wavelengths to the production of different sizes of Au nanoparticles by picosecond laser ablation in water, as well as the different ablation mechanisms, and suggested that "at higher energy per pulse, and correspondingly higher fluence, material extraction by multiphoton absorption dominates over heating effects".

Haustrup and O'Connor [42] identified the existence of a linear relationship between the size of the Au nanoparticles and the size of the grain produced at both 343 and $515 \mathrm{~nm}$ wavelengths, whereas there is no relationship at $1030 \mathrm{~nm}$ wavelength ablation. This is due to the inter-band absorption effects at the shorter wavelengths, which results in faster electron-phonon coupling and higher electron temperatures that process produces thermoelastic stresses in the target material. On the other hand, no inter-band absorption occurs at a wavelength of $1030 \mathrm{~nm}$; thus, the absorption occurs by intra-band absorption and the ablation process takes place over longer timescales, resulting in the removal of the grain boundaries prior to production of the nanoparticles [42].

A problem with comparing the effect of different wavelengths in producing nanoparticles in a liquid solution is the different beam absorption characteristics of the nanoparticles at different laser wavelengths. For example, Ag nanoparticles are more efficient for self-absorption at the 532-nm wavelength than at the 1064-nm wavelength because of the surface plasmon bands that form at around $400 \mathrm{~nm}$ [3]. In addition, the absorption coefficient $\alpha$ is a function of the wavelength.

Different laser wavelengths also have different responses to energy loss within the water above the target materials. As a result different size of the nanoparticles would be produced, if the energy loss was not corrected. As shown in Fig. 11, it can be seen that the water level has a strong effect on the laser power at the 1064-nm wavelength, while it has a negligible effect at the 532-nm wavelength. For example, at a 2-mm water level, about 5.5 and $0.004 \%$ of the laser power will be lost at 1064 and $532 \mathrm{~nm}$ wavelengths, respectively. This is because water has a strong absorption coefficient at $1064 \mathrm{~nm}$ and a weak absorption coefficient at $532 \mathrm{~nm}$. The relationship between laser power loss (expressed as a percentage) and water level is linear for both wavelengths. 


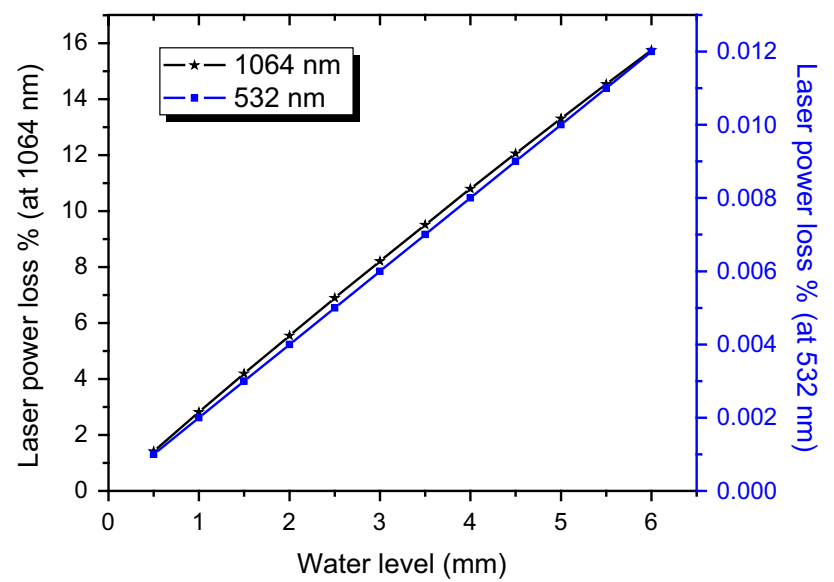

Fig. 11 Laser power loss at 532 and $1064 \mathrm{~nm}$ wavelengths due to water level above the sample during generation of nanoparticles

The laser beam focal length will be increased in water. As shown in Fig. 12a, the amount of increased focal length is directly proportional to the water height. In water, the focal length will be increased when it passes through a liquid medium. This effect is increased during ablation under water at ultra-short wavelengths such as picosecond and femtosecond lasers due to refraction and self-focusing inside the liquid medium [43, 44].

The focal length will increase according to the following equation [44]:

$\Delta f=l\left(1-\frac{1}{n}\right)$

In the above equation $\Delta f$ is the amount by which the focal length increases in water, $l$ is the water level above the target material, and $n$ is the refractive index of the liquid medium. This fraction of focal length must be compensated while focusing the laser beam on the target material in the water; in other words, the distance between the lens and the target should be increased depending on the height of the liquid above the sample. As shown in Fig. 12a, the amount of increased focal length is directly proportional to the water height. This effect is the same at both 532 and $1064 \mathrm{~nm}$ because focal length does not depend on the wavelength.

While focusing the laser beam on the target sample in water, the distance between the scan head and the target material should be increased (see Fig. 12b). For example, at a water level of $2 \mathrm{~mm}$ above the sample, the focal distance should be increased by about $0.5 \mathrm{~mm}$ and for $4 \mathrm{~mm}$ this distance should be $1 \mathrm{~mm}$. It is worth mentioning that the focal length of the laser-focusing lens and the position of the target material have a significant effect on the size distribution and the shape of the nanoparticles produced [2].

Refractive index declines with the increase in wavelength, so a smaller refractive index means higher laser beam refraction in the media leads to change the ablation area (or marking area) in comparison with the program made marking area. This could explain why a smaller scanned area was produced on the target surface in comparison with the CNC program made. Here, at $532 \mathrm{~nm}$, the laser produced smaller scan area than the 1064-nm wavelength. Here, $1064 \mathrm{~nm}$ produced larger scan area than the 532-nm wavelength because the longer wavelength gives smaller change in refractive index. Due to this reason longer laser wavelength leads to considerably higher ablation efficiency [45].

\subsection{Effects of Wavelengths on the Crystallinity of Metal Oxide Nanoparticles}

XRD patterns show that the iron oxide nanoparticles are crystalline with mixed $\mathrm{Fe}, \mathrm{FeO}$ and $\mathrm{Fe}_{3} \mathrm{O}_{4}$. $\mathrm{FeO}$ may be (a)

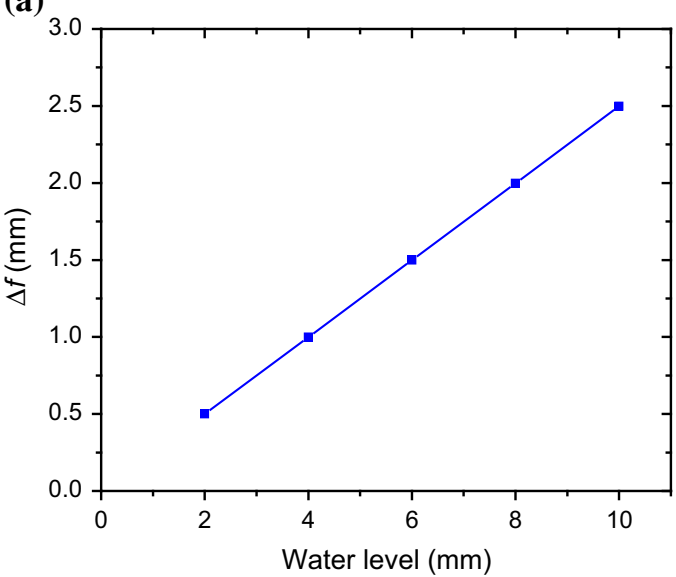

(b)

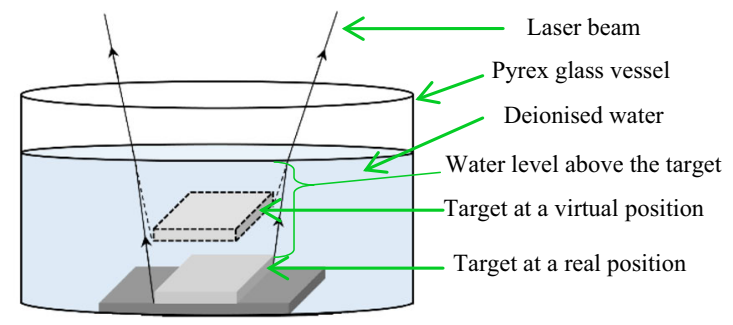

Fig. 12 Increase in focal length of the lens of a laser tool as a function of height above water level (a). Real and virtual depth of the target material (b) 
produced according to Eqs. (2) and (3) [16]. The interaction between the laser beam and the Fe target material produces $\mathrm{Fe}$ clusters. Then they will interact with the liquid solution leading to the production of $\mathrm{Fe}(\mathrm{OH})_{2}$ and hydrogen release. Due to the high temperature and high pressure at the target-liquid interface, $\mathrm{FeO}$ would be produced [16].

$$
\begin{aligned}
& \mathrm{Fe} \text { (clusters) }+2 \mathrm{H}_{2} \mathrm{O} \rightarrow \mathrm{Fe}(\mathrm{OH})_{2}+\mathrm{H}_{2} \\
& \mathrm{Fe}(\mathrm{OH})_{2} \longrightarrow \text { high Temp. \& PressureFeO }+\mathrm{H}_{2} \mathrm{O}
\end{aligned}
$$

Because $\mathrm{Fe}$ exists in a wide range of oxidation states, redox reactions must be taken into account. The existence of the different types iron oxides dependent upon to different redox reactions [46].

$\mathrm{Fe}(\mathrm{s}) \rightarrow \mathrm{Fe}^{2+} \rightarrow \mathrm{Fe}^{3+}$

As shown in Eq. (5), $\mathrm{Fe}_{3} \mathrm{O}_{4}$ can be produced by controlled oxidation of $\mathrm{Fe}^{2+}$ in solution:

$3 \mathrm{Fe}^{2+}+\mathrm{O}_{2}+2 \mathrm{OH}^{-} \rightarrow \mathrm{Fe}_{3} \mathrm{O}_{4}+2 \mathrm{H}^{+}$

Zero-valent iron $\left(\mathrm{Fe}^{o}\right)$ can be obtained according to Eq. (6) [47]:

$\mathrm{Fe}^{2+}+2 \mathrm{e}^{-} \rightarrow \mathrm{Fe}^{o}$

During laser interaction with the $\mathrm{Zn}$ target material in deionised water, $\mathrm{ZnO}$ nanoparticles could be produced according to the following equations [48].

$\mathrm{H}_{2} \mathrm{O}+h v \rightarrow \mathrm{H}^{+}+\mathrm{OH}^{-}$

$\mathrm{OH}^{-}+h v \rightarrow \mathrm{O}^{*}+\mathrm{H}^{*}$

$\mathrm{Zn}+\mathrm{O} \rightarrow \mathrm{ZnO}$

After laser interaction with the $\mathrm{Ti}$ target, Ti cluster or $\mathrm{Ti}$ vapour will be produced; then, they interacted with water to produce titanium (IV) hydroxide $\mathrm{Ti}(\mathrm{OH})_{4}$. Finally, $\mathrm{TiO}_{2}$ nanoparticles will be produced according to Eqs. (10) and (11) [49].

$\mathrm{Ti}($ cluster $)+\mathrm{H}_{2} \mathrm{O} \rightarrow \mathrm{Ti}(\mathrm{OH})_{4}+\mathrm{H}_{2} \uparrow$
$\mathrm{Ti}(\mathrm{OH})_{4} \rightarrow \mathrm{TiO}_{2}+\mathrm{H}_{2} \mathrm{O}$

XRD characterisation shows that the crystallinity of titanium dioxide is strongly dependent upon the laser wavelengths, as the formation of the titanium dioxide phases (anatase, rutile and brookite) depends on temperature. Iron oxide nanoparticles are slightly dependent upon the laser wavelength, but the wavelength has no effect on crystalline $\mathrm{ZnO}$ nanoparticles. In other words, the oxide materials with more crystalline phases are affected by laser wavelength. XRD patterns show that the $\mathrm{TiO}_{2}$ nanoparticles produced at a wavelength of $532 \mathrm{~nm}$ are more crystalline than those produced at $1064 \mathrm{~nm}$. The wavelength of $532 \mathrm{~nm}$ can produce mixed anatase, rutile and brookite phases of $\mathrm{TiO}_{2}$ nanoparticles, but the wavelength of $1064 \mathrm{~nm}$ can only produce rutile and brookite phases. A strong rutile peak was observed at optical absorption spectra of $532 \mathrm{~nm}$ at $27.5^{\circ}$. In addition, some small peaks of the anatase and rutile phases were observed at the 532-nm wavelength. These small peaks were produced when the sample was annealed at 500 and $800{ }^{\circ} \mathrm{C}$ for $2 \mathrm{~h}$. According to the last case, the 532-nm laser wavelength may produce a higher temperature than the $1064 \mathrm{~nm}$. Crystalline phases are easily produced within materials that have a low phase-transition temperature [50].

Phase transition of the $\mathrm{TiO}_{2}$ is not only affected by wavelength, but also by the laser beam mode such as pulsed or continuous wave (CW). Single-phase rutile $\mathrm{TiO}_{2}$ was obtained at $553-952{ }^{\circ} \mathrm{C}$ using a $\mathrm{CW} \mathrm{CO}_{2}$ laser at $1064 \mathrm{~nm}$ wavelength, while the rutile changed to anatase with increasing deposition temperature from 579 to $957^{\circ} \mathrm{C}$ using a Nd:YAG laser at $1064 \mathrm{~nm}$ [51].

The laser power and the type of target material are important in order to control the uniformity of the iron oxide phases. Furthermore, liquid environments have an effect on the crystallinity of the iron oxide phases; for example, in this work, crystalline maghemite $\left(\alpha-\mathrm{Fe}_{2} \mathrm{O}_{3}\right)$ nanoparticles were not produced because of the use of deionised water. Conversely, laser ablation of an iron oxide target material in acetone and ethanol produces crystalline maghemite $\left(\gamma-\mathrm{Fe}_{2} \mathrm{O}_{3}\right)$ nanoparticles [52]. The crystallinity of the iron oxide nanoparticles increases with increasing laser energy [53]. However, for better understanding, further study of this topic is required.

\section{Conclusions}

This study has investigated the effects of two laser wavelengths (532 and $1064 \mathrm{~nm}$ ) of a picosecond laser on the size and size distribution of the $\mathrm{Au}, \mathrm{Ag}, \mathrm{Ag}-\mathrm{TiO}_{2}$, $\mathrm{TiO}_{2}, \mathrm{ZnO}$ and iron oxide nanoparticles in deionised water. The results show that slightly smaller metal oxide nanoparticles $\left(\mathrm{TiO}_{2}, \mathrm{ZnO}\right.$ and iron oxide) were produced at the 1064-nm wavelength. In spite of higher laser fluence at $532 \mathrm{~nm}$ than that at $1064 \mathrm{~nm}$, significant reduction of particle size was seen for the production of pure $\mathrm{Au}$ and $\mathrm{Ag}-\mathrm{TiO}_{2}$ nanoparticles at the $532-\mathrm{nm}$ wavelength showing more dominating effect of laser wavelength. Pure $\mathrm{Ag}$ nanoparticles could not be produced at the 532-nm laser wavelength of the picosecond laser, but $\mathrm{Ag}-\mathrm{TiO}_{2}$ nanoparticles were produced by using a Ti/Ag alloy as a target material. It was found that the water level above the target material does not have a significant effect on the loss of laser intensity at the 532-nm wavelength, but at $1064 \mathrm{~nm}$ wavelength the laser intensity was significantly reduced. It was also found that the formation of crystalline $\mathrm{TiO}_{2}$ nanoparticles was strongly dependent upon the wavelength. 
Open Access This article is distributed under the terms of the Creative Commons Attribution 4.0 International License (http://crea tivecommons.org/licenses/by/4.0/), which permits unrestricted use, distribution, and reproduction in any medium, provided you give appropriate credit to the original author(s) and the source, provide a link to the Creative Commons license, and indicate if changes were made.

\section{References}

1. R. Singh, R. Soni, Improved catalytic activity of laser generated bimetallic and trimetallic nanoparticles. J. Nanosci. Nanotechnol. 14(9), 6872-6879 (2014)

2. H. Imam, K. Elsayed, M.A. Ahmed, R. Ramdan, Effect of experimental parameters on the fabrication of gold nanoparticles via laser ablation. Opt. Photonics J. 2, 73-82 (2012)

3. F. Hajiesmaeilbaigi, A. Mohammadalipour, J. Sabbaghzadeh, S. Hoseinkhani, H. Fallah, Preparation of silver nanoparticles by laser ablation and fragmentation in pure water. Laser Phys. Lett. 3(5), 252 (2006)

4. A. Baladi, R.S. Mamoory, Study on wavelength and energy effects on pulsed laser ablation synthesis of aluminum nanoparticles in ethanol, in MEMS, NANO, and Smart Systems (ICMENS), 2009 Fifth International Conference on 2009: IEEE (2009)

5. S.Z. Mortazavi, P. Parvin, A. Reyhani, A.N. Golikand, S. Mirershadi, Effect of laser wavelength at IR $(1064 \mathrm{~nm})$ and UV $(193 \mathrm{~nm})$ on the structural formation of palladium nanoparticles in deionized water. J. Phys. Chem. C 115(12), 5049-5057 (2011)

6. J. Kim, D.A. Reddy, R. Ma, T.K. Kim, The influence of laser wavelength and fluence on palladium nanoparticles produced by pulsed laser ablation in deionized water. Solid State Sci. 37, 96-102 (2014)

7. P. Chewchinda, T. Tsuge, H. Funakubo, O. Odawara, H. Wada, Laser wavelength effect on size and morphology of silicon nanoparticles prepared by laser ablation in liquid. Jpn. J. Appl. Phys. 52(2R), 025001 (2013)

8. C. He, T. Sasaki, Y. Shimizu, N. Koshizaki, Synthesis of ZnO nanoparticles using nanosecond pulsed laser ablation in aqueous media and their self-assembly towards spindle-like $\mathrm{ZnO}$ aggregates. Appl. Surf. Sci. 254(7), 2196-2202 (2008)

9. R. Intartaglia, G. Das, K. Bagga, A. Gopalakrishnan, A. Genovese, M. Povia, E. Di Fabrizio, R. Cingolani, A. Diaspro, F. Brandi, Laser synthesis of ligand-free bimetallic nanoparticles for plasmonic applications. Phys. Chem. Chem. Phys. 15(9), 3075-3082 (2013)

10. E. Giorgetti, A. Giusti, F. Giammanco, P. Marsili, S. Laza, Dendrimer-capped nanoparticles prepared by picosecond laser ablation in liquid environment. Molecules 14(9), 3731-3753 (2009)

11. A. Hamad, L. Li, Z. Liu, X.L. Zhong, H. Liu, T. Wang, Generation of silver titania nanoparticles from an $\mathrm{Ag}-\mathrm{Ti}$ alloy via picosecond laser ablation and their antibacterial activities. RSC Adv. 5(89), 72981-72994 (2015)

12. A. Hamad, L. Li, Z. Liu, A comparison of the characteristics of nanosecond, picosecond and femtosecond lasers generated $\mathrm{Ag}$, $\mathrm{TiO}_{2}$ and $\mathrm{Au}$ nanoparticles in deionised water. Appl. Phys. A 120(4), 1247-1260 (2015)

13. A. Schwenke, P. Wagener, S. Nolte, S. Barcikowski, Influence of processing time on nanoparticle generation during picosecondpulsed fundamental and second harmonic laser ablation of metals in tetrahydrofuran. Appl. Phys. A 104(1), 77-82 (2011)

14. K. Nouneh, M. Oyama, G. Lakshminarayana, I. Kityk, A. Wojciechowski, K. Ozga, Kinetics of picosecond laser treatment of silver nanoparticles on ITO substrate. J. Alloys Compd. 509(40), 9663-9668 (2011)

15. A. Menéndez-Manjón, A. Schwenke, T. Steinke, M. Meyer, U. Giese, P. Wagener, S. Barcikowski, Ligand-free gold-silver nanoparticle alloy polymer composites generated by picosecond laser ablation in liquid monomer. Appl. Phys. A 110(2), 343-350 (2013)

16. P. Liu, W. Cai, H. Zeng, Fabrication and size-dependent optical properties of $\mathrm{FeO}$ nanoparticles induced by laser ablation in a liquid medium. J. Phys. Chem. C 112(9), 3261-3266 (2008)

17. T.K. Ghorai, Synthesis of spherical mesoporous titania modified iron-niobate nanoclusters for photocatalytic reduction of 4-nitrophenol. J. Mater. Res. Technol. 4(2), 133-143 (2015)

18. P. Anandgaonker, G. Kulkarni, S. Gaikwad, A. Rajbhoj, Nanocrystalline titanium dioxide catalyst for the synthesis of azlactones. Chin. J. Catal. 35(2), 196-200 (2014)

19. J. Yan, G. Wu, N. Guan, L. Li, Z. Li, X. Cao, Understanding the effect of surface/bulk defects on the photocatalytic activity of $\mathrm{TiO}_{2}$ : anatase versus rutile. Phys. Chem. Chem. Phys. 15(26), 10978-10988 (2013)

20. T.A. Kandiel, L. Robben, A. Alkaim, D. Bahnemann, Brookite versus anatase $\mathrm{TiO}_{2}$ photocatalysts: phase transformations and photocatalytic activities. Photochem. Photobiol. Sci. 12(4), 602-609 (2013)

21. Y. Li, N.-H. Lee, D.-S. Hwang, J.S. Song, E.G. Lee, S.-J. Kim, Synthesis and characterization of nano titania powder with high photoactivity for gas-phase photo-oxidation of benzene from TiOCl2 aqueous solution at low temperatures. Langmuir 20(25), 10838-10844 (2004)

22. K. Gupta, R. Singh, A. Pandey, A. Pandey, Photocatalytic antibacterial performance of $\mathrm{TiO}_{2}$ and $\mathrm{Ag}$-doped $\mathrm{TiO}_{2}$ against $S$. aureus. P. aeruginosa and E. coli. Beilstein. J. Nanotechnol. 4(1), 345-351 (2013)

23. Y. Li, J. Li, M. Ma, Y. Ouyang, W. Yan, Preparation of $\mathrm{TiO}_{2} /$ activated carbon with $\mathrm{Fe}$ ions doping photocatalyst and its application to photocatalytic degradation of reactive brilliant red K2G. Sci. China, Ser. B: Chem. 52(8), 1113-1119 (2009)

24. S.S. Mukunda-Rao, K. Natarajan, Antibiofilm Activity of Epoxy/ Ag-TiO2 Polymer Nanocomposite Coatings against Staphylococcus aureus and Escherichia coli, in Photocatalytic Coatings for Air-Purifying, Self-Cleaning and Antimicrobial Properties, ed. by A. Maury-Ramirez (MDPI, Basel, Switzerland, 2015), p. 3

25. P. Ramasamy, D.-M. Seo, S.-H. Kim, J. Kim, Effects of $\mathrm{TiO}_{2}$ shells on optical and thermal properties of silver nanowires. J. Mater. Chem. 22(23), 11651-11657 (2012)

26. Lopez, J.A., F. González, F.A. Bonilla, G. Zambrano and M.E. Gómez, Synthesis and characterization of $\mathrm{Fe}_{3} \mathrm{O}_{4}$ magnetic nanofluid. Rev. Latinoam. Metal. Mater. 30(1), 60-66 (2010)

27. S. Wu, A. Sun, F. Zhai, J. Wang, W. Xu, Q. Zhang, A.A. Volinsky, $\mathrm{Fe}_{3} \mathrm{O}_{4}$ magnetic nanoparticles synthesis from tailings by ultrasonic chemical co-precipitation. Mater. Lett. 65(12), 1882-1884 (2011)

28. S. Sharma, J. Vargas, K. Pirota, S. Kumar, C. Lee, M. Knobel, Synthesis and ageing effect in $\mathrm{FeO}$ nanoparticles: transformation to core-shell $\mathrm{FeO} / \mathrm{Fe}_{3} \mathrm{O}_{4}$ and their magnetic characterization. J. Alloys Compd. 509(22), 6414-6417 (2011)

29. Y. Hou, Z. Xu, S. Sun, Controlled synthesis and chemical conversions of $\mathrm{FeO}$ nanoparticles. Angew. Chem. 119(33), 6445-6448 (2007)

30. R.J. Joseyphus, K. Shinoda, D. Kodama, B. Jeyadevan, Size controlled $\mathrm{Fe}$ nanoparticles through polyol process and their magnetic properties. Mater. Chem. Phys. 123(2), 487-493 (2010)

31. Z. Yuanbi, Q. Zumin, J. Huang, Preparation and analysis of $\mathrm{Fe}_{3} \mathrm{O}_{4}$ magnetic nanoparticles used as targeted-drug carriers. Chin. J. Chem. Eng. 16(3), 451-455 (2008) 
32. R. Gabbasov, M. Polikarpov, V. Cherepanov, M. Chuev, I. Mischenko, A. Lomov, A. Wang, V. Panchenko, Mössbauer, magnetization and X-ray diffraction characterization methods for iron oxide nanoparticles. J. Magn. Magn. Mater. 380, 111-116 (2015)

33. R.M. Alwan, Q.A. Kadhim, K.M. Sahan, R.A. Ali, R.J. Mahdi, N.A. Kassim, A.N. Jassim, Synthesis of zinc oxide nanoparticles via sol-gel route and their characterization. Nanosci. Nanotechnol. 5(1), 1-6 (2015)

34. Y.T. Prabhu, K.V. Rao, V.S.S. Kumar, B.S. Kumari, Synthesis of $\mathrm{ZnO}$ Nanoparticles by a novel surfactant assisted amine combustion method. Adv. Nanoparticles 2(01), 45 (2013)

35. M.R. Arefi, S. Rezaei-Zarchi, Synthesis of zinc oxide nanoparticles and their effect on the compressive strength and setting time of self-compacted concrete paste as cementitious composites. Int. J. Mol. Sci. 13(4), 4340-4350 (2012)

36. S. Dutta, B.N. Ganguly, Characterization of $\mathrm{ZnO}$ nanoparticles grown in presence of Folic acid template. J. Nanobiotechnol. 10(1), 1-10 (2012)

37. A. Hamad, L. Li, Z. Liu, X.L. Zhong, G. Burke, T. Wang, The characteristics of novel bimodal $\mathrm{Ag}-\mathrm{TiO}_{2}$ nanoparticles generated by hybrid laser-ultrasonic technique. Appl. Phys. A 122(4), $1-12(2016)$

38. M. Takahashi, Y. Takada, M. Kikuchi, O. Okuno, Released ions and microstructures of dental cast experimental $\mathrm{Ti}-\mathrm{Ag}$ alloys, in Interface Oral Health Science 2007 (Springer, 2007), pp. 311-316

39. U. Gurudas, E. Brooks, D.M. Bubb, S. Heiroth, T. Lippert, A. Wokaun, Saturable and reverse saturable absorption in silver nanodots at $532 \mathrm{~nm}$ using picosecond laser pulses. J. Appl. Phys. 104(7), 73107 (2008)

40. G. Rong, H. Wang, L.R. Skewis, B.M. Reinhard, Resolving subdiffraction limit encounters in nanoparticle tracking using live cell plasmon coupling microscopy. Nano Lett. 8(10), 3386-3393 (2008)

41. G. Rong, H. Wang, B.M. Reinhard, Insights from a nanoparticle minuet: two-dimensional membrane profiling through silver plasmon ruler tracking. Nano Lett. 10(1), 230-238 (2009)

42. N. Haustrup, G. O'Connor, Impact of wavelength dependent thermo-elastic laser ablation mechanism on the generation of nanoparticles from thin gold films. Appl. Phys. Lett. 101(26), 263107 (2012)

43. A. Menéndez-Manjón, P. Wagener, S. Barcikowski, Transfermatrix method for efficient ablation by pulsed laser ablation and nanoparticle generation in liquids. J. Phys. Chem. C 115(12), 5108-5114 (2011)

44. Z. Yan, D.B. Chrisey, Pulsed laser ablation in liquid for micro-/nanostructure generation. J. Photochem. Photobiol. C Photochem. Rev. 13(3), 204-223 (2012)

45. A. Baladi, R.S. Mamoory, Effect of laser wavelength and ablation time on pulsed laser ablation synthesis of Al nanoparticles in ethanol, in International Journal of Modern Physics: Conference Series. 2012: World Scientific

46. R. Bosinceanu, N. Sulitanu, Synthesis and characterization of $\mathrm{FeO}(\mathrm{OH}) / \mathrm{Fe}_{3} \mathrm{O}_{4}$ nanoparticles encapsulated in zeolite matrix. J. Optoelectron. Adv. Mater. 10(12), 3482-3486 (2008)

47. Y.-P. Sun, X.-Q. Li, J. Cao, W.-X. Zhang, H.P. Wang, Characterization of zero-valent iron nanoparticles. Adv. Colloid Interface Sci. 120(1), 47-56 (2006)

48. M. Gondal, Q. Drmosh, Z. Yamani, T. Saleh, Synthesis of $\mathrm{ZnO}_{2}$ nanoparticles by laser ablation in liquid and their annealing transformation into $\mathrm{ZnO}$ nanoparticles. Appl. Surf. Sci. 256(1), 298-304 (2009)

49. S.M. Hong, S. Lee, H.J. Jung, Y. Yu, J.H. Shin, K.-Y. Kwon, M.Y. Choi, Simple Preparation of Anatase $\mathrm{TiO}_{2}$ Nanoparticles via pulsed laser ablation in liquid. Bull. Korean Chem. Soc. 34, 279-282 (2013)

50. A.V. Kolobov, Photo-induced metastability in amorphous semiconductors (Wiley, Chichester, 2006)

51. M. Gao, A. Ito, T. Goto, Effect of laser wavelength on phase and microstructure of $\mathrm{TiO}_{2}$ films prepared by laser chemical vapor deposition. Surf. Coat. Technol. 244, 166-172 (2014)

52. P. Maneeratanasarn, T.V. Khai, S.Y. Kim, B.G. Choi, K.B. Shim, Synthesis of phase-controlled iron oxide nanoparticles by pulsed laser ablation in different liquid media. Phys. Status Solidi (a) 210(3), 563-569 (2013)

53. P. Maneeratanasarn, T. Khai, B. Choi, K. Shim, The effect of laser energy on the preparation of iron oxide by a pulsed laser ablation in ethanol. J. Korean Cryst. Growth Cryst. Technol. 22(3), 134-138 (2012) 